\title{
Циркониевая минерализация в аповулканитовых метасоматитах Ловозерского щелочного массива
}

\author{
Михайлова Ю.А., Пахомовский Я.А., Калашников А.О., Яковенчук В.Н., Базай А.В., \\ Иванюк Г.Ю. \\ Геологический институт КНЦ РАН, Anamumbl, ylya_korchak@mail.ru
}

\begin{abstract}
Аннотация. В статье обсуждается формирование циркониевой минерализации при фенитизации вулканитов основного состава. Образование собственных фаз циркония связано с привносом $\mathrm{Zr}$ щелочными расплавами-растворами, а состав этих фаз обусловлен волнообразным изменением концентрации щелочей. Первым кристаллизуется циркон, затем, при максимальной щелочности, паракелдышит, который сменяется эвдиалитом. При изменении паракелдышита образуется бадделеит.

Ключевые слова: базальты, туфы, фенитизация, Ловозерский массив, цирконий, паракелдышит, эвдиалит, циркон, бадделеит.
\end{abstract}

\section{Zirconium mineralization in apo-volcanic metasomatites of the Lovozero alkaline massif}

\author{
Mikhailova Yu.A., Pakhomovskiy Ya.A., Kalashnikov A.O., Yakovenchuk V.N., Bazai A.V., \\ Ivanyuk G.Yu. \\ Geological Institute KSC RAS, Apatity,ylya_korchak@mail.ru
}

\begin{abstract}
The article discusses the formation of zirconium mineralization during fenitization of volcanic rocks of basic composition. The formation of own zirconium phases is associated with the addition of zirconium with alkaline melt-solutions, and the composition of these phases is due to the wave-like change in alkali concentration. Zircon crystallizes first, then, with maximum alkalinity, parakeldyshite and eudialyte. Baddeleyte is formed by changing parakeldyshite.
\end{abstract}

Key words: basalt, tuff, fenitization, Lovozero massif, zirconium, parakeldyshite, eudialyte, zircon, baddeleyite.

Ловозерский щелочной массив - это расслоенный лакколит, внедрившийся $370 \pm 7$ млн. лет назад (Kramm and Kogarko, 1994) в архейские гнейсы и перекрывающую их толщу пород трапповой формации. Массив состоит из двух крупных комплексов: эвдиалитового и дифференцированного (рис. 1 а). Эвдиалитовый комплекс залегает вверху разреза, составляет 18 \% объема массива и внутренним расслоением не обладает. Он сложен нефелиновыми сиенитами, обогащенными минералами группы эвдиалита (эвдиалитовыми луявритами). На долю дифференцированного комплекса приходится 77 \% объема массива, расслоение в нем проявлено четко. Элементарной единицей расслоенности здесь является последовательность (ритм) щелочных пород (снизу вверх): уртит-фойяит-луяврит (малиньит). В этом ряду происходит постепенный переход от почти мономинеральных нефелиновых фоидолитов (уртитов) к лейкократовым нефелиновым сиенитам (фойяитам), а затем к мезо- и меланократовым нефелиновым сиенитам (луявритам). Последовательность уртит-фойяит-луяврит повторяется регулярно (Герасимовский и др., 1966; Буссен, Сахаров, 1972).

Среди щелочных пород дифференцированного и эвдиалитового комплексов, подчиняясь общей расслоенности массива, расположены пластовые или линзовидные ксенолиты вулканогенноосадочных пород трапповой формации (ловозерской свиты). В неизмененном виде эти породы представлены оливиновыми базальтами, базальтовыми туфами и туффитами и сложены форстеритом, диопсидом-авгитом, плагиоклазом (олигоклазом-андезином), флогопитом, ильменитом и кварцем в переменных пропорциях (Korchak, 2011).

Степень контактово-метасоматической переработки (фенитизации) пород ксенолитов различна. Характер минеральных ассоциаций образующихся фенитов полностью зависит от температуры. При изначально высокой температуре $\left(750-800^{\circ} \mathrm{C}\right)$ процесс фенитизации начинается с образования пород роговиковой структуры, состоящих из анортоклаза, ортоклаза, аннита, секанинаита, герци- 


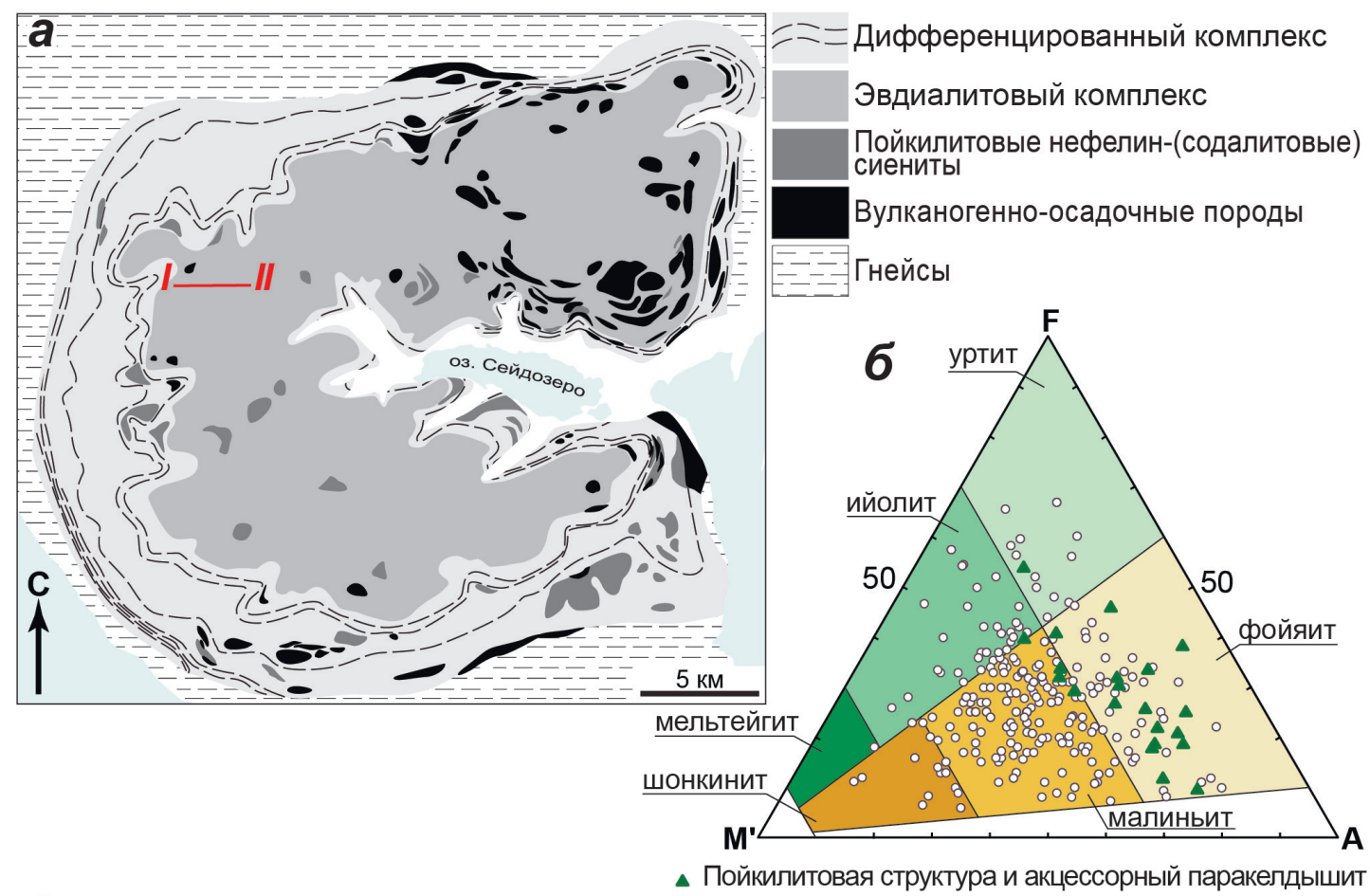

B

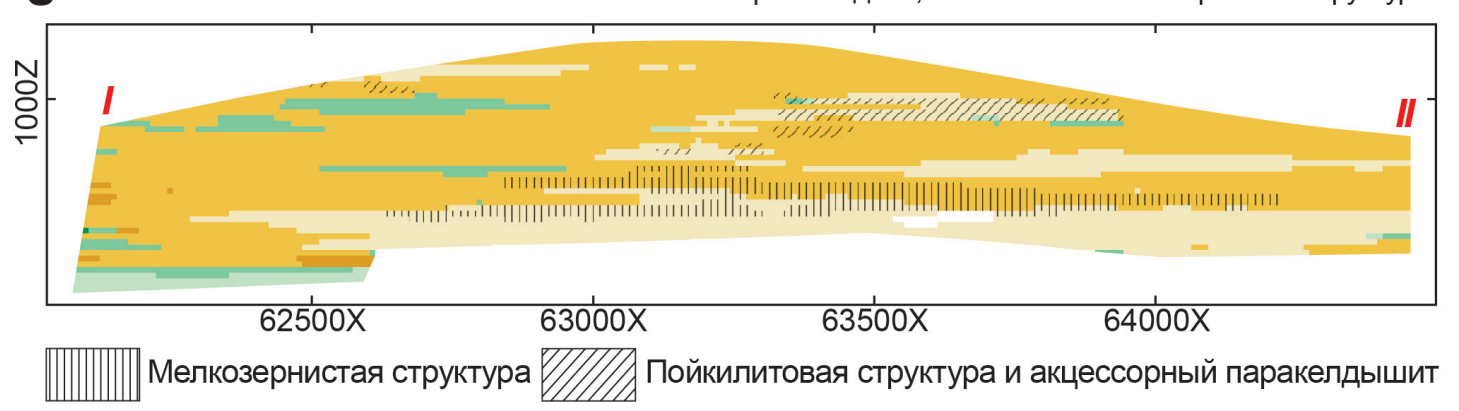

Рис. 1. а - схема геологического строения Ловозерского массива по (Буссен, Сахаров, 1972), с дополнениями; б - модальный состав щелочных пород Аллуайвского участка согласно данным подсчёта площадей зёрен в шлифах. Зелеными треугольниками выделены породы пойкилитовой структуры, содержащие паракелдышитфторапатит-титанитовую ассоциацию; в - разрез по линии I-II (см. рис. 1 а). Цвета соответствуют рис. 1 б. Штриховками выделены мелкозернистая и пойкилитовая структуры соответствующих пород.

Fig. 1. a - the scheme of the geological structure of the Lovozero massif after (Bussen, Sakharov, 1972), as supplemented; $b$ - modal composition of alkaline rocks of the Alluaive locality according to the data of calculation of grain areas in thin polish sections. Green triangles indicate rocks of poikilitic structure containing parakeldyshite-fluorapatite-titanite association; $\mathrm{c}$ - section along the line I-II (see Fig. 1a). Colors correspond to Fig. 1 b. Fine-grained and poikilitic structures of the corresponding rocks are highlighted by shading.

нита и ильменита. По мере падения температуры в роговиках появляются эгирин-(авгит), альбит, нефелин и щелочные амфиболы (арфведсонит, магнезиоарфведсонит), т.е. ассоциация, почти аналогичная вмещающим нефелиновым сиенитам и фоидолитам. Спецификой аповулканитовых метасоматитов является обогащение фторапатитом и титанитом. При низкотемпературной фенитизации стадия ороговикования отсутствует (Korchak, 2011).

Крупный пласт аповулканитовых метасоматитов обнаружен нами при исследовании пород Эвдиалитового комплекса в районе гор Аллуайв и Куамдеспакх (профиль I-II на рис. 1 а). Преобладающими плутоническими породами здесь являются малиньиты (рис. 1 б), в том числе мелкозернистые, в толще которых расположены субгоризонтальные залежи ийолитов, шонкинитов, фойяитов и уртитов (рис. 1 в). Переходы между всеми этими породами постепенные, структура их трахитоид- 
ная либо массивная. Пласт пород, модально соответствующих фойяитам (реже - уртитам, рис. 1 б), но обладающих паракелдышит-фторапатит-титанитовой акцессорной минерализацией и пойкилитовой структурой, располагается наклонно и имеет мощность до 120 метров. Нетипичная акцессорная минерализация отличает метасоматиты от других пород пойкилитовой структуры - нефелин(содалитовых) сиенитов (рис. 1а).

Основу структуры метасоматитов составляют (1) пойкилокристаллы ортоклаза $\left(\mathrm{Or}_{44-57} \mathrm{Ab}_{40-51}\right)$ и ортоклаз-пертита с включениями нефелина, содалита, вишневита; (2) идиоморфный крупный нефелин. Полевой шпат насыщен мелкими (до 20 мкм) включениями фторапатита, титанита, лопарита, эгирина, сфалерита. В породе большое количество резорбированных реликтов диопсида и/ или авгита, окруженных каймами сначала эгирин-авгита, а затем, снаружи, рихтерита и/или феррикатофорита. Характерны симплектитовые срастания магнезиоарфведсонита с нефелином, окруженные каймами эгирина. Внутри магнезиоарфведсонита и на его границе с эгирином сосредоточены крупные зерна фторапатита, титанита (рис. 2 a), ильменита и лопарита. Эгирин, кроме кайм, образует веерообразные агрегаты в интерстициях зерен полевого шпата и нефелина.
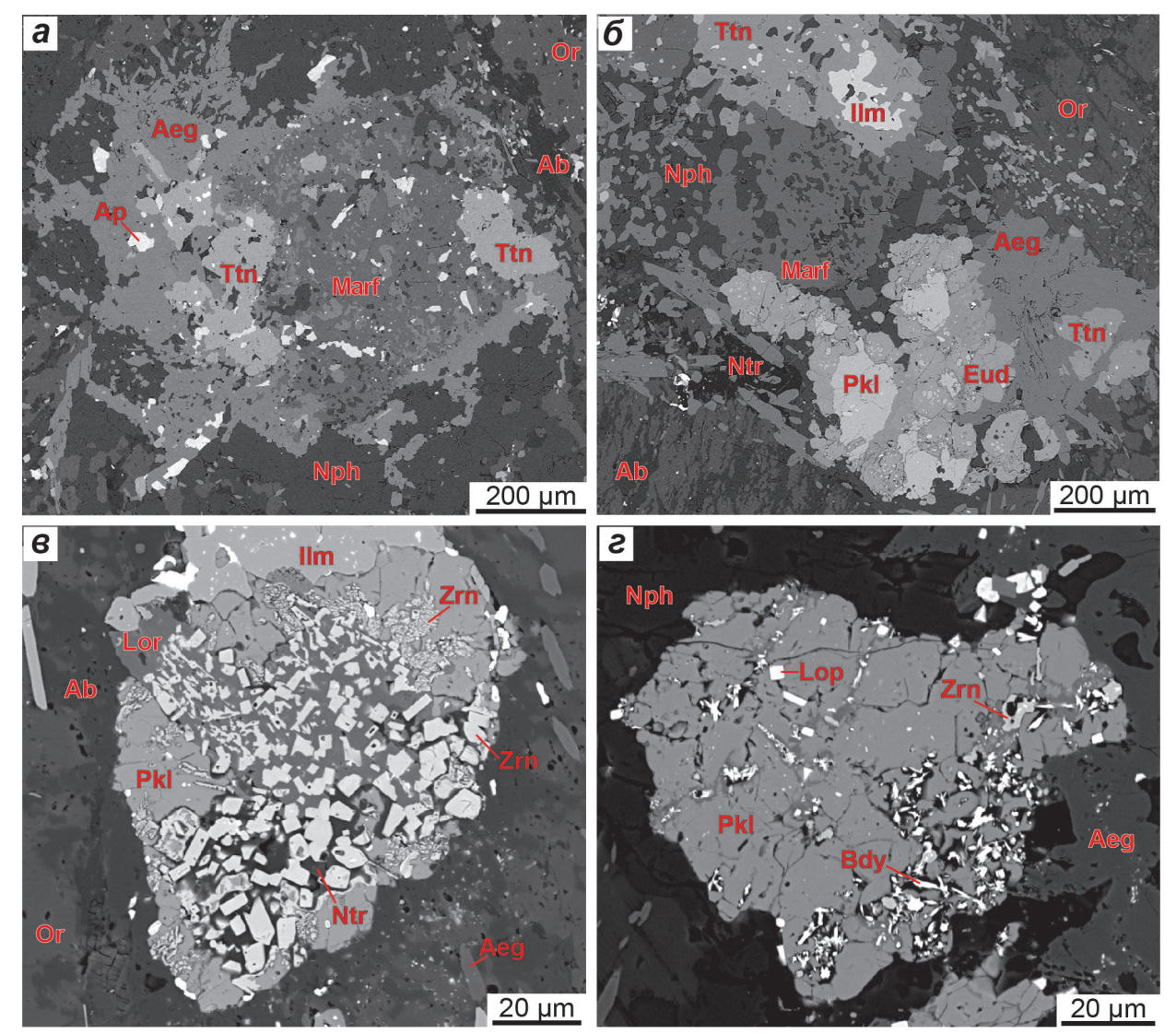

Рис. 2. а - срастания магнезиоарфведсонита и нефелина, окруженное каймой эгирина и насыщенное включениями титанита и фторапатита (образец 157/63); б - зерна паракелдышита, окруженные каймами эвдиалита в ассоциации с эгирином и титанитом (образец 156/98); в - срастания циркона с лоренценитом, натролитом и паракелдышитом (образец 156/77); г - бадделеит, циркон и лопарит внутри зерен паракелдышита (образец 156/77). Фото в обратно-рассеянных электронах. Aeg - эгирин; Ab - альбит; Ap - фторапатит, Bdy - бадделеит, Eud - эвдиалит; Ilm - ильменит, Lop - лопарит; Marf- магнезиоарфведсонит; Nph - нефелин; Ntr - натролит, Or - ортоклаз, Pkl - паракелдышит; Ttn - титанит, Zrn - циркон.

Fig. 2. a - magnesioarfvedsonite and nepheline, surrounded by aegirine and saturated with inclusions of titanite and fluorapatite (sample 157/63); б - parakeldyshite grains surrounded by eudialyte rims in association with aegirine and titanite (sample 156/98); в - fusion of zircon with lorenzenite, natrolite, and parakeldyshite (sample 156/77); $\Gamma$-baddeleyite, zircon, and loparite inside the parakeldyshite grains (sample 156/77). BSE-images. Aeg - aegirine; Ab - albite; Ar - fluorapatite, Bdy - baddeleyite, Eud - eudialyte; Ilm - ilmenite, Lop - loparite; Marf- magnesioarfvedsonite; Nph - nepheline; Ntr - natrolite, Or - orthoclase, Pkl - parakeldyshite; Ttn - titanite, Zrn - zircon. 
Минералы циркония в этих породах представлены паракелдышитом, эвдиалитом, цирконом и бадделеитом. Все они приурочены к зернам амфиболов и пироксенов (рис. 2 a, б). Паракелдышит формирует мелкие (до 400 мкм в поперечнике) округлые или неправильной формы зерна с многочисленными мелкими (до 10 мкм) включениями лопарита. Снаружи зерна паракелдышита окружены каймами эвдиалита (рис. 2 б). Реже в составе кайм присутствуют титанит, фторапатит и ильменит. Внутри эвдиалита расположены мелкие включения лопарита. С паракелдышитом часто ассоциирует циркон, который образует либо отдельные мелкие кубические кристаллы внутри паракелдышита, либо агрегаты мелких зерен в срастаниях с паракедышитом. Паракелдышит также обрастает вокруг симплектитовых срастаний циркон+лоренценит, циркон+натролит (рис. 2 в), циркон+эгирин. Кроме паракелдышита, перечисленные симплектитовые срастания циркона могут быть окружены мелкими зернами эвдиалита. Вместе с цирконом внутри паракелдышита встречаются мелкие призматические кристаллы бадделеита. Они располагаются вместе с цирконом в небольших полостях рыхлого агрегата зерен паракелдышита, но чаще цепочками внутри паракелдышита в ассоциации с фазой, по составу близкой к келдышиту.

Неизмененные породы ловозерской свиты (оливиновые базальты, туфы, туффиты) не содержат минералов циркония по причине низкого содержания этого элемента (максимально 0.01 мас. \% $\mathrm{ZrO}_{2}$ ). Цирконий здесь рассеян в породообразующих темноцветных минералах. В аповулканитовых метасоматитах содержание циркония на порядок выше и достигает 0.48 мас. \% $\mathrm{ZrO}_{2}$ ), что свидетельствует о привносе этого элемента щелочными расплавами-растворами в процессе фенитизации. Осаждение циркония, по-видимому, непосредственно следует за кристаллизацией щелочных пироксенов и амфиболов. Об этом свидетельствуют взаимоотношения минералов в шлифах (например, призматические кристаллы эгирина внутри паракелдышита и эвдиалита), а также постоянная примесь циркония в составе эгирина (до 1.02 мас. \% $\mathrm{ZrO}_{2}$ ) и магнезиоарфведсонита (до 0.67 мас. \% $\mathrm{ZrO}_{2}$ ), наличие которой возможно только в отсутствие собственных минералов циркония. Разнообразие фаз циркония обусловлено постепенным нарастанием концентрации щелочей в ходе фенитизации пород ксенолитов. Ранняя (относительно эгирина) кристаллизация магнезиоарфведсонита свидетельствует о повышенной концентрации Si и относительно низкой щелочности, что приводит к образованию циркона (Piilonen et al., 1998). Относительно раннему формированию циркона, вероятно, также благоприятствует повышенное содержание фтора (Farges et al., 1991) на начальном этапе фенитизации, о чем свидетельствует одновременное образование фторапатита. Кристаллизация эгирина приводит к увеличению содержания щелочей относительно кремния (Mikhailova et al., 2017), что стабилизирует паракелдышит. Эвдиалит образуется позже паракелдышита на завершающей стадии фенитизации на фоне падения концентрации щелочных компонентов. Бадделеит является самым поздним из минералов циркония. Он, вероятно, образуется в результате изменения паракелдышита.

Исследования проводились в рамках научной темы ГИ КНЦ РАН 0226-2019-0051 при финансовой поддержке Президиума РАН (Программа I-48).

\section{Литература}

1. Буссен И.В., Сахаров А.С. Петрология Ловозерского щелочного массива. Л. Изд-во: Наука. 1972.296 с.

2. Герасимовский В.И., Волков В.П., Когарко Л.Н., Поляков А.И., Сапрыкина Т.В., Балашов Ю.А. Геохимия Ловозерского щелочного массива. М. Изд-во: Наука. 1966395 с.

3. Farges F., Ponader C. W., Brown Jr G. E. Structural environments of incompatible elements in silicate glass/melt systems: I. Zirconium at trace levels // Geochimica et Cosmochimica Acta. 1991. T. 55. № 6. C. 1563-1574.

4. Korchak Y.A., Men'shikov Y.P., Pakhomovskii Y.A., Yakovenchuk V.N. \& Ivanyuk G.Y. Trap formation of the Kola Peninsula. Petrology. 2011. V. 19(1). P. 87-101.

5. Kramm U., Kogarko L.N. Nd and Sr isotope signatures of the Khibina and Lovozero agpaitic centres. Kola Alkaline Province. Russia // Lithos. 1994. T. 32. № 3-4. C. 225-242.

6. Mikhailova J.A. et al. REE mineralogy and geochemistry of the Western Keivy peralkaline granite massif. Kola Peninsula. Russia // Ore Geology Reviews. 2017. T. 82. C. 181-197.

7. Piilonen P.C., McDonald A.M., Lalonde A.E. The crystal chemistry of aegirine from Mont Saint-Hilaire, Quebec // The Canadian Mineralogist. 1998. T. 36. № 3. C. 779-791. 